\title{
Applied Research on Design Semiotics
}

\author{
Rui-Bo HU ${ }^{1, a,{ }^{*}}$, Xiao-Song Zhang ${ }^{1, b}$, Xin-Yu SUO ${ }^{2, \mathrm{c}}$, Yuan $\mathrm{HU}^{1, \mathrm{~d}}$ \\ ${ }^{1}$ Guizhou Normal University, Guiyang, P.R.China \\ ${ }^{2}$ Yunnan University of Nationalities School of Vocational technical Educayion, Kunming, P.R.China \\ amysjgzs@126.com, b407904118@qq.com, '1014707295@qq.com, d282250069@qq.Com \\ ${ }^{*}$ Corresponding author
}

Keywords: design semiotics, visual, indicative and symbolic

\begin{abstract}
. study the concept of design semiotics, analyze the "significance system", "one stands for another", "truth system and generalization system" and the "syntax rules of symbol " of symbol, combine the case of product design, analyze the value of symbol in product design, obtain three basic functions of design semiotics that is "visual", "indicative" and "symbolic".
\end{abstract}

\section{Introduction}

The concept of symbol. As to its traditional definition a symbol is "one stands for another", this concept is quite simple in some extent. The author thinks that: symbol is a meaningful transfer medium, is an informosomes with highly realistic and highly summarized in the process of one stands for another. It is an informosomes that people can interpret according to certain rule and context in the same cultural background and language environment. It is called symbol (Fig.1). Here it can be interpreted differently: first of all, the meaningful transmission medium means transmission for necessary, there would be no need to transmit without significance.

Zhao Yiheng in "semiotics" deeply research on significance system. He thinks: "the symbol is the meaning, no symbol no meaning, semiotics is significs." Secondly, in the process of one stands for another, there is informosomes with highly realistic and highly summarized, in the process of the informosomes reacts the expressed informosomes, need to react the characteristics of another things need to express. What kind of characteristics? That is its authenticity and generality. On the contrary, if the informosomes does not have authenticity and generality? There are three kinds of situation, one is the feature reflects informosomes is not real. This state is pointless, and without meaning also is not symbol.

The second situation is the symbol in the specific era background, reacting the authenticity of informosomes for the development and changes of times, that is the real response. The third situation is reader's misunderstanding. Again, readers can interpret the information according to certain rule and context in the same cultural background and language environment. For example, suppose two people are in communication, one is a Chinese (don't understand English) and the other is the British (don't understand Chinese, don't know about the cultural background of China), at that time, they only can communicate with body language and sign language, then it is difficult to communicate. Readers have the same cultural background, here is the basic requirement for interpret informosomes, in the process of interpreting symbols, reader have to try to understand the coding rule and context of coder, only so can interpret things more close to the intention of the coder. 


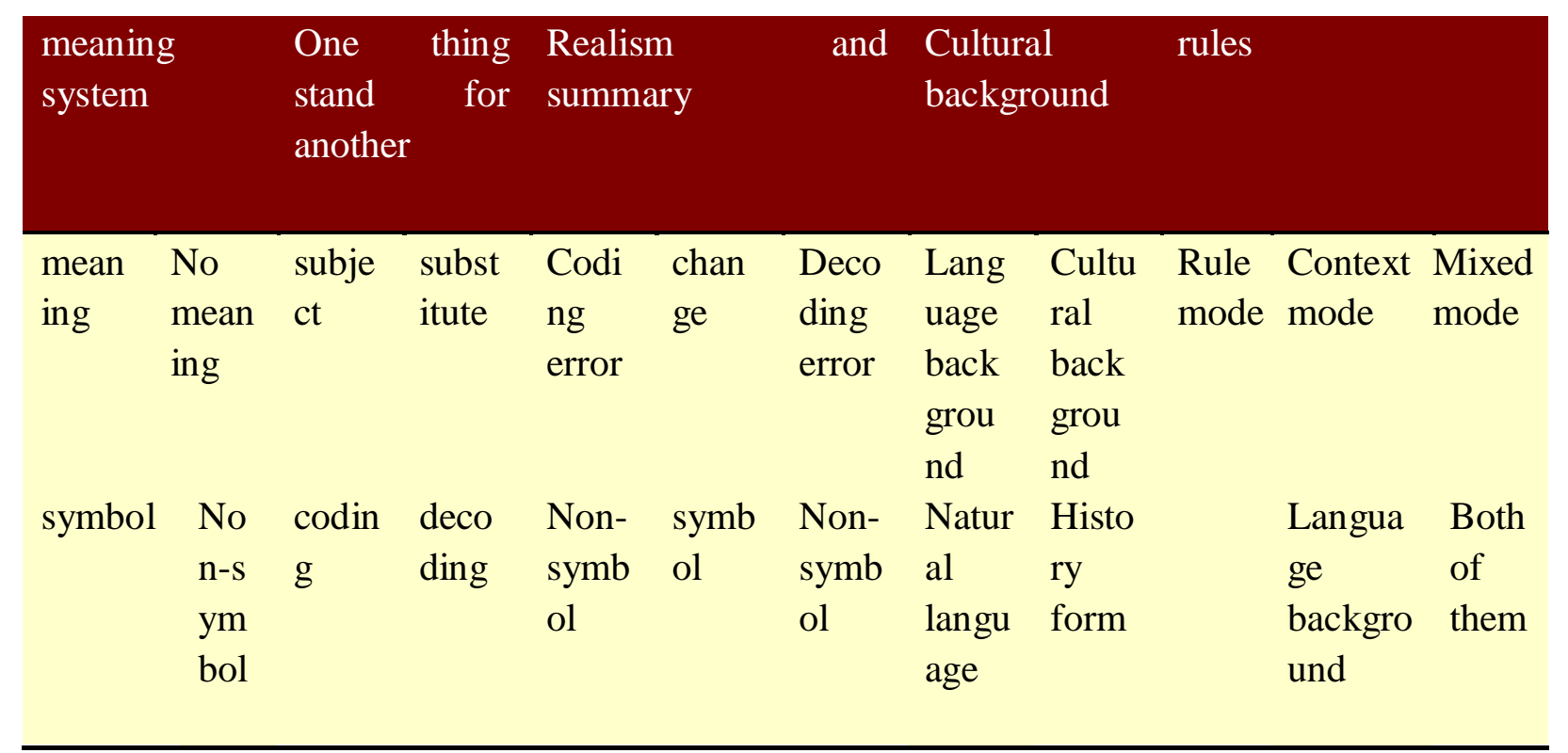

Fig. 1 the course of symbol's formation

\section{Symbol is a meaningful transmission}

Zhao Yiheng in the book "semiotics", said: "meaning is a symbol, has the potential to be described by other symbols, explanation is the implementation of significance. As a result, he makes his further inference: meaning must be explained by symbols, in turn says, no meaning can be explained without symbol ." In pottery design, for example, the purpose of its design is a decorative vase, to make its design with aesthetic, pick up the morphology of peacock and ox horn to design, to make the design works form meaning system. In the process of observation, you feel the design works like something else, when you think of the design works like something, and then it has formed a meaning system. At the same time, the viewer can design work according to this, combined with its own cultural accomplishment, design work can be interpreted. Therefore, symbol is a meaningful transmission (as shown in Fig.2).

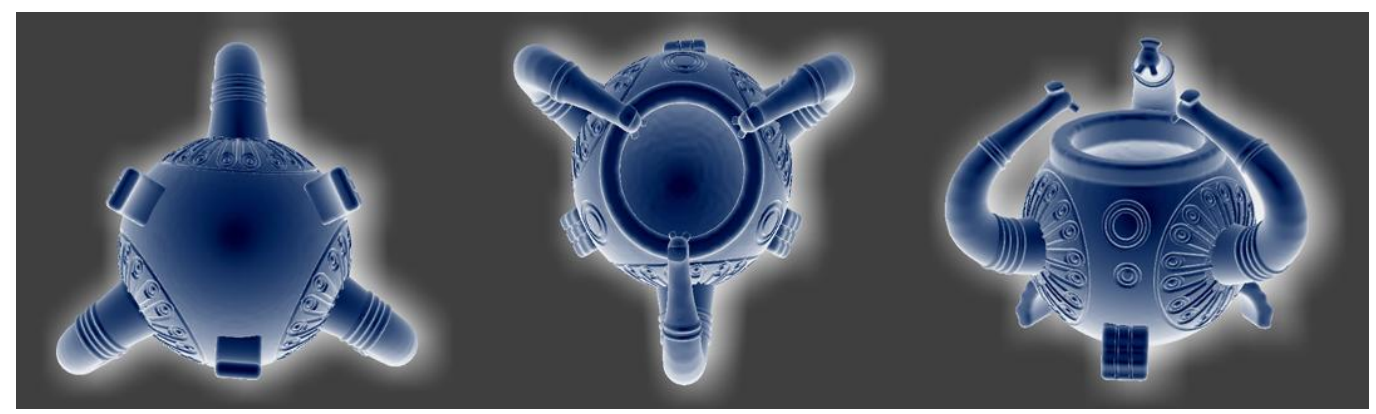

Fig.2 element: The peacock and the shape of the horn

\section{Symbol has a common cultural background}

Having the same cultural background refers to share a common language background and the customs formed in the long process of history. From the perspective of communication, two monomers can communicate freely without using hand gestures and body language. For lifestyle, two people have a common language, historical development, and the production and living habits. 
For example, in the national ceramics of Yunnan, the traditional Tibetan black pottery is the oldest traditional folk crafts, with 4000 years of history, among them black pottery in Nixi village,Shangri-la is the most famous.

Tibetan black pottery is black in color, simple in modeling, unique in style, with the features of Tibetan style, generosity, plain, kindliness, natura and original ecology, some even adorned with white porcelain, black and white contrast, conspicuous and chic. Tibetan black pottery in Nixi has more than ten varieties such as caddy, kettle, wine, which is not only the Tibetan people's living utensils, supplying for all people to use nearby, but also be purchased and collected by tourists at home and abroad as traditional folk arts and crafts. The austere black pottery is still the living appliances and furnishings for Tibetans in modern. Tibetan in Nixi village, Shangri-la, are still passing on the Gordon type pottery which has a history of 4000 - year - old .Since thousands of years the craft, the modelling and function never changed, make the traditional craft products disjointed between the development of modern society, industry shrink, lack of subsequent talent, especially the backward mode of production lead to low productivity, is difficult to meet the needs of modern society.

\section{Symbol has its high authenticity and high generality}

Having high authenticity refers to after one stands for another, in addition to the functions of itself, the object also can be seen clearly. In product modeling design, as shown in figure 9, is the designed children's table using the combination of seven siphon worm and butterfly element, where the so-called one transfers to another, refers to the designer wants to use seven siphon worms and butterfly elements to design a set of tables when he is beginning to design. And after finishing design, most of the features of this "thing"still can be seen clearly. With high generality refers to the process that one conveys to another, in the process of conveying, use some characteristics of the object, but has a high degree of generality, if not to see carefully, it would be difficult to see some of the characteristics of the object.

\section{The composition of the symbol has rule}

This argument, the author expounds carefully in the first chapter, this paper will divide its into three basic types, rule model, context model and mix model. The author here mainly applies it to the industrial product design. There are plenty of examples for the use of rules for design, mainly including the use of golden section, arithmetic progression, comparative sequence, harmonic progression, Fibonacci sequence, perl sequence, and so on. logarithmic spiral of shellfish is defined to follow the golden section. The golden ratio everyone is familiar with is $1: 1.618$ or $0.618: 1$, this theorem is the psychological reaction made by German psychologist Fechner in late 19th century when he was studying the attributes of a rectangle has the special beauty. Here as for the design, if put the shellfish into a rectangular, then have it do golden cut constantly and connect it, and then take the crossover between golden section and rectangle tangency and the next golden section as round dot, and take golden line as the radius to draw arc, finally, get a very perfect spiral line.

\section{The type of design symbol}

visual symbols. The so-called visual symbol refers to the phenomenon that graphical representation is objective, namely the fact of imitating "visual similar". There are many instances of images of semeiology, such as photographs and portrait painting are belong to signs in icon, 
bionic design of products design also is a typical example of image symbol. In this sense, the image of symbol has a function of reproducibility. Word "reproducibility" blurs the expression meaning for real object, reproducibility is different from the intact copy and imitate for outside world. Then, art reproduction is the embodiment that makes the image resort to ink, text or sculpture, on the basis of the soul reproduction. And image representation is the recreation for the most beautiful things in reality and the concern and expression for the nature of ordinary things. Representational image is not the exact copy of natural things by man, nor ban for the fine details of overelaborate, but designers intuitive feelings of nature and the cognition, reality and expression for its spiritual essence and the attention for humanities spirit.

indicative symbol.(1) System indicative symbol.Modern scholars Wang Guowei in "Yin \& Zhou system theory", put inheritance for the oldest son principal wife, the years of working as a official and no marriage within the same family name this three system as a fundamental difference between Shang and Zhou civilization. He thinks "Chinese political and cultural change, just belong to Yin \& Zhou". In Western Zhou Dynasty patriarchal clan system is restricted and developed more, including the system of put inheritance for the oldest son born to the principal wife, the years of working as a official and no marriage within the same family name has a further expansion, and formed well-planned and ordered patriarchal clan system. Those related to patriarchal clan system is feudalism, including the emperor is "big clanlaw" in the country that is "kingdom" who embodies politics, patriarchal clan system and religious leaders as a whole. Seigneur is "small clanlaw ", pay tribute and make the hajj to the emperor on schedule, and dispatch troops according to the emperor's requirement, etc. The "community drinking rituals" in Shang and Zhou Dynasties stresses to respect the leaders and honor the older, discuss military and political together. China is a state of ceremonies, the "ritual and musical systems", not only refers to the song, dance, melody,but also includes all the artistic conventions and recognizant specification matched with the etiquette system.

The indicate of guide recognition system. The components of guide recognition system contain images, symbol, text and brand Micro-target, etc. Whether its design embodies the fundamental elements becomes the key to success for the recognition system. Behrens, designed for German general company AEG with building design, visual communication design and product design in 1909,among which the graphic design he designed for AEG, including product catalogs, ads, posters, etc.,made unified design for the whole high image from the the products to the corporate image and sales, through the following changes of dozens of drafts, it have been using to today. The "arrow symbol", evolved by the arrow, which is common in the indicator system. The reasonable use of arrow decides the identification and directional of information. Arrow has the meaning of move, direction, stop, etc. in the guiding sign system. Arrow has a multiple use, except to express front, rear, right and left, also can express slant, turning, lift, etc.

symbolic symbol. Word symbolize has wider significance, widely being used in philosophy, logic, mathematics, linguistics, and humanities as well as in everyday life. Imply certain people or things by borrowing something with specific image, to express the sincere feelings and profound implication. Its effect of expression is graceful conception, that can enrich people's association, and thought-provoking, that can help people get endless artistic conception, which can give people a real feeling of conciseness and image, thus can express sincere feelings. The symbol of ancestor-worship. A record of the worship dragon and tiger is very common. People often use dragon and tiger in comparison or use they combined name to express the majestic land, emperors'gifts and bold strategy, military and political leaders' great foresight and the people's 
great momentums. Until today, people still use "Dragons Rising and Tigers Leaping", "Like a Lively Dragon and an Active Tiger" to metaphor for workers, farmers, the people's liberation army, intellectuals, and the fighting spirit of vigorous young students. In the history of the civilization of Chinese nation, Xia dynasty has "Dragon Flag and Tiger Calendar"; Shang dynasty has "Dragon and Tiger Statue"; Zhou and Qin dynasty has:"Dragon and Tiger Knob"; Liu Bang has " Dragon and Tiger Vigour"; Master of Confucian classics in the Eastern Han dynasty has written "Dragon and Tiger Poem"; Zhu Geliang has "Prance Like the Dragon and Watch Like the Tiger" Tang and Song dynasty has a "Dragon and Tiger Announcement"; Until today, there are the saying "Like a Lively Dragon and an Active Tiger" .

(2) The symbol of power. Famous postmodernism architect Venturi in his book the complexity and contradiction of building pointed out that building should be historical contextual, and the national, against the international style, and points out the construction should transmit some kind of significance. For the royal architecture in China, building in the palace, most of them be built by resplendent and magnificent huge roof, vermeil wooden colonnade, doors and Windows, and pure white white marble stylobate. the beams, doors and windows of palace architecture are all built by wood, and were painted with vermilion and gold that symbolizes joy and rich. In some places, covered with the color painting such as dragon-phoenix, sea of clouds, flowers and plants. Bright colors, continuous embodies the luxury of imperial house .

(3) The symbol of age.Life of Dai nationality women in Dehong can be divided into four stages: one is "Xiao Ren" (young girl) group, less than 13 years old, wear white shirt and black trousers, bound hair with cyan or belt; The second is "Bu Shao " (maid) group, 15 years old or so, wear white shirt and black trousers, tie with black embroidered corset and belt, plait hair tie with red belt; Third is "Bi Lang" (married middle-aged women) group, and the dark blue skirt of black or white socks, don't wear corset and belts, covered head with white or black cloth; Four is "Mi Ba" (older women) group, all wear with black shirt, black dress and black turban. Similarly, in furniture design, children's furniture like to use the colorful color, for young people, they like concise design, and for the old, they like relatively deep colour to show the sedate and sophisticated.

(5)The symbol of area.The symbol of area refers to the display of culture symbol and specialization that can represent the regional characteristics. In China, the south of the Yangtze river is called as Jiangnan, as for Jiangnan, once talk about it, weeping willows, rainy, bamboo and other natural phenomena and biology will be thought. And in Chinese garden design, like to use technique of borrowing scenery and enframing scenery confined with rainy weather memory remain fresh in people's memory. For example, the ceramic design take lotus leaf as its elements, lotus is a pretty common aquatic plant in the south of the Yangtze river, when it comes to lotus, also can recollect the impression with Jiangnan. Then, how the feature of Jiangnan is formed? No doubt, it must be formed with characteristics elements, compared with the characteristics of Jiangbei district. It is generally known that Jiangbei has the features of rare rainfall, corresponding with the rainy weather in Jiangnan. Therefore, symbol have the function of regional division.

Fund project: ministry of science and technology support project (SQ2013BAJY4603); The protection of ethnic culture and display technology application demonstration ".In composition Triassic palaeontologic heritage site protection and application demonstration of characteristic culture. "125" science and technology major special projects in guizhou province department of education(20012) 007]: guizhou ethnic arts and crafts industrialization development of tourism Author introduction: Ruibo Hu, a man was born in December ,comes form the DaoZhou county of 
HuNan province,master of lecturer, engaged in the tourism products, landscape, rhetoric art,research of ethnic costumes. E-mail:mysjgzs@126.com

Corresponding author: Renpin Xu,a man was born in 1949,comes from Shanghai province professor, $\mathrm{PhD}$ supervisor. Product design, national folk art, national costumes, visual communication design.E - mail: xurenp@gmail.com

\section{References}

[1] Xu Renping. Techniques of Quick Prototype and Development of Quick Products [J]. Beingjing: Chemical Industry Press, 2008

[2] Zhong Fumin. Symbolic Study of the Chinese Lucky Patterns [M]. Beijing: China Social Science, 2009.11:105-107

[3] Xu Hengchun. The Study of Symbols Design [M]. Beijing: Tsinghua University Press, 2008.7:26

[4] Gan Yang translate, Ernst Cahill write. Human [M]. Shanghai: Shanghai Translation Press, 1985.7: 40-41

[5] Duclos and Tordolphin edit. Encyclopedic Dictionary of Science of Language, English Translation [M] Hopkins University Press, 1979

[6] Maurice. Signs, Language and Behavior [M] New York 1955 Edition: 8

[7] Fromm. The Forgotten Language [M]. New York 1951 English Edition, Page 12

[8] Carl Jung. Salvation of Souls of Modern People [M]. London 1947 English Edition, page 15

[9] Fraser. Significant and Meaning [M] Reproduced by Magazine of Philosophy and Critic Philosophy, Suy Press, 1892 10-100

[10] Derry. The Design and Convey of Language in Product Pattern Design [M]. Beijing: Higher Education Press, 2008.8:22 